\title{
The role of dance therapy in the rehabilitation of Parkinson disease patients
}

\author{
NEMES Bianca Oana ${ }^{1}$, PIRLOG Radu ${ }^{2,3}$, TARTAMUS Dorina ${ }^{4}$, CAPUSAN Camelia $^{5}$, FODOR Dana Marieta $^{6}$
}

Corresponding Author: PIRLOG Radu, E-mail: pirlog.radu@umfcluj.ro

2. Research Center for Functional Genomics Biomedicine and Translational Medicine, "Iuliu Hatieganu" University of Medicine and Pharmacy, Cluj-Napoca, Romania 3. Department of Morphological Sciences, “Iuliu Hatieganu” University of Medicine and Pharmacy, Cluj-Napoca, Romania 4. "Puterea Sperantei Project, Cluj-Napoca, Romania 5."LaVitaMed" Clinic, Cluj-Napoca, Romania 6. "Iuliu Hatiegau" University of Medicine and Pharmacology, Cluj-Napoca, Romania

\section{Abstract}

Introduction: Parkinson disease is the second most common neurodegenerative disease which requires a complex approach including pharmacological and non-pharmacological treatment. While kinesiotherapy is a must in Parkinson's disease patients, dance therapy in rehabilitation programs is not often taken into consideration. Dance therapy is a challenging non-pharmacological treatment which merges physical activity with musical synchronization, socialization, disease acceptance and creativity with daily activities. The aim of this study is to evaluate the effect of dance therapy on the quality of life, functionality and decrease of depression in Parkinson patients.

Material and method: We developed a case control study to evaluate the benefit of dance therapy in Parkinson Patients. The study group consisted in 10 patients from "Puterea Sperantei Project". The intervention consisted in 40 minutes/day of dance therapy during two weeks. First control group consisted of 10 patients admitted to Cluj-Napoca Rehabilitation Hospital for two weeks. The second control group consisted in 5 patients enrolled in the "Puterea Sperantei Project" which did not attended dance classes. All three groups followed standard therapy: kineto-therapy and ergo-therapy. To assess the effect of dance therapy we used: Beck scale, Parkinson Disease Questionnaire (PDQ39) and a satisfaction questionnaire which we developed, for the dance therapy.

Results and discussions: In the study group we registered an improvement of depression symptoms $(p=0,017)$ and an increase in the life quality $(\mathrm{p}=0,005)$. In the hospital control group and in the "Puterea Speratei Project" control group there was no decrease in the depressions score $(p>0,05)$. However, the quality of life increased also in the control group enrolled in the Rehabilitation Hospital, probably due to medication change. The mean of satisfaction questionnaire for dance therapy in the study group was 39,70 from a maximum of 48 points.

Conclusions: Dance therapy is a holistic non-pharmacological therapy which improves the depression index, the quality of life and functionality of Parkinson disease patients. This initial results raise the possibility of including dance therapy as an alternative of non-pharmacological therapy in the rehabilitation programs for Parkinson Disease Patients.

Key words: Parkinson disease, dance therapy, non-pharmacological therapy, depression, quality of life,

\section{Introduction}

Parkinson disease is the second commonest neurodegenerative disease, after Alzheimer disease. It affects $1 \%$ of elderly population over 60 years old $(1,2)$. Parkinson disease is a chronic pathology that evolves slowly to disability, and currently, doesn't have a cure (3). It is characterized by bradykinesia, rigidity, resting tremor and gait impairment $(4,5)$. Additional features can include non-motor symptoms like sleep disorders, sensory alteration, cognitive impairment and depression which are poorly recognized and inadequately treated (6).

Treatment in Parkinson disease is based on pharmacological and non-pharmacological therapies.
The gold standard in pharmacological treatment remains Levodopa which is a precursor of dopamine (7). Other categories of medications are: cathecol-Omethyltransferase inhibitor, monoamine oxidase inhibitors and dopamine agonists $(2,3)$.

Even if the majority of patients are treated with specific medication to overcome the dopamine deficit, part of them still experience motor and nonmotor symptoms (8). Therefore, the treatment approach must be a holistic one in order to maintain the quality of life in these patients as much as possible. Most used non-pharmacological therapies are in daily practice are: cognitive behavioral 
therapy, occupational therapy, kinesiotherapy, speech therapy $(8,9)$.

Dance therapy is a new non-pharmacological therapy that can be seen as an alternative to common exercises, which includes a combination of rhythm, music and socialization of participants (10). Dancing has a strong background in every community, making it a pleasant activity for everyone. It was shown that dancing can have a positive influence on depression symptoms and can help patients better integrate in communities and increase their quality of life $(8,11)$. For the human brain, music can offer one of the most powerful motor, cognitive, sensorial and emotional experience $(12,13)$. It influences the central nervous system, neuroendocrine system, increase the cognitive functions and activates areas in the brain, such as temporal, frontal, parietal and occipital $(11,14)$.

The effect of music on long term therapy is probably the one of neuroplasticity, which includes the neurogenesis of hippocampus, increase the level of brain derived neurotrophic factor in hypothalamus and hippocampus, which have a positive responses $(10,15,16)$. The aim of our study was to evaluate the effect of two weeks daily dance therapy on the quality of life, depression symptoms in Parkinson disease patients.

\section{Materials and Method}

In our study we enrolled 25 patients, 10 in the study group, 10 in the hospital control group and 5 in the "Puterea Sperantei Project" control group. The two control groups were selected to overcome the small number of patients and to identify the possibility of other variables with the effect produces by the dance therapy. All patients included in the study followed the same non-pharmacological therapies: kinesiotherapy and ergotherapy. The only difference was that in the hospital control group, in which patients medication might have been changed due to their symptoms, while the ones from the study group had stable medication during the study period. Three questionnaires were applied: Beck Scale to evaluate the degree of depression, Parkinson's Disease Questionnaire (PDQ39) to assess the quality and functionality of life and a satisfaction questionnaire which quantified the level of satisfaction for dance therapy. In order to quantify the satisfaction questionnaire we used the Likert scale with five possibility of answer, where 0 is minimum and 4 is maximum (17). In the questionnaire were included 12 questions (see Appendix) about dance therapy and did it influence their daily routine, the quality of the information given by the dance therapy coordinator and also a general opinion about the project.

Beck Scale and PDQ-39 were applied in all three groups at the beginning and at the end of the study, while the satisfaction questionnaire was applied at the end of the study, only to the study group which benefited from dance therapy $(18,19)$. The intervention consisted of two weeks of everyday dance classes for 40 minutes.

The dance rehabilitation program was adapted according to the moves presented by Dance for Parkinson's disease (20). Our program was adjusted in order to involve every patient in the activity. The choreography was developed around daily routine events, starting from simple to complex moves and required visualisation, synchronization, rhythm, socialization, physical effort and concentration from participants. Exercises aimed to give to the patients the context to express freely and, with the aid of music, to move fluently.

All statistical analyses were performed in $\mathrm{R}$ environment for statistical computing and graphics, version 3.2.3. Wilcoxon pair test was applied to analyze Beck and PDQ39 scores. A p $<0,05$ was considered as statistical significant.

\section{Results}

The study included 25 Parkinson disease patients, 22 were from urban environment and 3 from rural environment. Mean age was 65 years old. According to Hoehn \& Yahr scale for Parkinson disease stage, $20 \%$ of the patient ( 5 patients) were stage $2,8 \%$ (2 patients) were stage $2.5,56 \%$ (14 patients) were stage $3.0,8 \%$ ( 2 patients) were stage 4.0 , the data from 2 patients was missing.

In the study group was a significant reduction in the depression score measured with the Beck test $(p=0,017)$ and an increase in the quality of life and functionality, evaluated with the PDQ-39 questionnaire $(p=0,017)$ (Table 1$)$. The mean score for the satisfaction questionnaire for dance therapy was 39,5 with a minimum of 34 and a maximum of 46 (Figure 1).

In the hospital control group there was no significant change in the depression score $(p=0,34)$, but it was observed an significant increase in the quality of life 
and functionality $(\mathrm{p}=0,008)$ (Table 2$)$.

In the "Puterea Sperantei Project" control group there was no significant change in the depression score ( $p=0,136)$, and the data from PDQ39(Table 3). questionnaires was missing due to lack of compliance (Table 3).

Table 1. Study group - Beck \& PDQ39 scales

\begin{tabular}{|ccccc|}
\hline \multirow{2}{*}{ Patients } & \multicolumn{2}{c}{ Initial values } & \multicolumn{2}{c|}{ Discharge values } \\
Beck & PDQ & Beck & PDQ \\
1 & 14 & 86 & 15 & 76 \\
2 & 8 & 17 & 6 & 9 \\
3 & 4 & 13 & 4 & 9 \\
4 & 6 & 24 & 4 & 15 \\
5 & 9 & 9 & 4 & 4 \\
6 & 5 & 21 & 1 & 20 \\
7 & 1 & 51 & 1 & 46 \\
8 & 6 & 52 & 1 & 18 \\
9 & 29 & 99 & 17 & 86 \\
10 & 9 & 38 & 5 & 18 \\
& & p 0,017 Beck & & \\
& p 0,005 PDQ39 & & \\
\hline
\end{tabular}

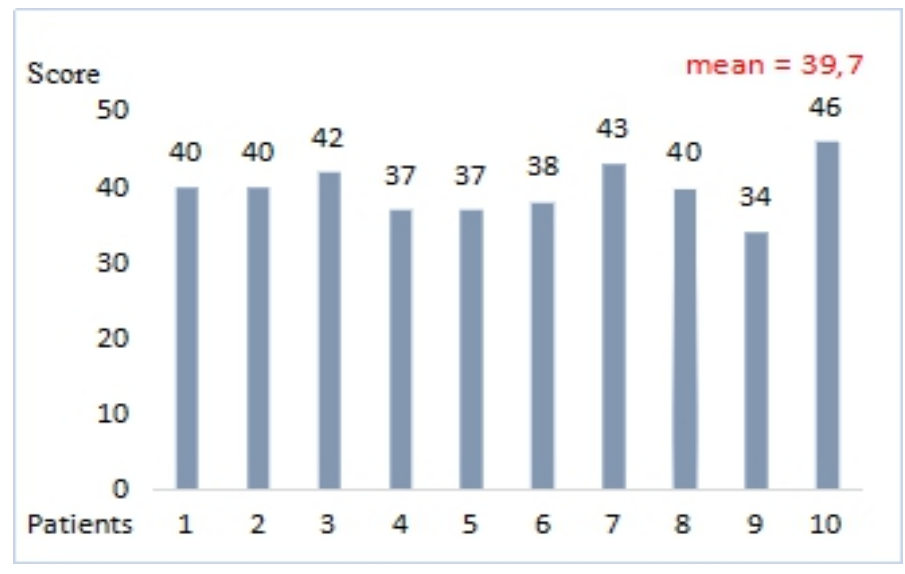

Fig. 1. Dance program satisfaction questionnaire

Table 2. Hospital control group-Beck \& PDQ39 scales

\begin{tabular}{|ccccc|}
\hline \multirow{2}{*}{ Patients } & \multicolumn{2}{c}{ Initial values } & \multicolumn{2}{c|}{ Discharge values } \\
& Beck & PDQ & Beck & PDQ \\
1 & 17 & 95 & 15 & 86 \\
2 & 12 & 28 & 10 & 27 \\
3 & 14 & 75 & 14 & 64 \\
4 & 7 & 51 & 4 & 39 \\
5 & 36 & 116 & 35 & 110 \\
6 & 26 & 70 & 26 & 70 \\
7 & 26 & 80 & 26 & 74 \\
8 & 28 & 90 & 28 & 82 \\
9 & 0 & 81 & 17 & 79 \\
10 & 18 & 106 & 16 & 92 \\
& \multicolumn{5}{c}{ p 0,34 Beck } & & \\
\hline
\end{tabular}

Table 3. "Puterea Sperantei" group - Beck scale

\begin{tabular}{|ccc|}
\hline Patients & $\begin{array}{c}\text { Initial Values } \\
\text { Beck }\end{array}$ & $\begin{array}{c}\text { Discharge values } \\
\text { Beck }\end{array}$ \\
1 & 45 & 44 \\
2 & 4 & 6 \\
3 & 12 & 7 \\
4 & 14 & 9 \\
5 & 13 & 10 \\
& p 0,136 Beck & \\
\hline
\end{tabular}

\section{Discussion}

We applied Beck scale in the study group at the beginning and the end of two-weeks-dance-therapy in order to evaluate depression symptoms and how dance therapy influenced them. We registered a statistic significance for the study group $(p=0,017)$, indicating that dance therapy improved depression's symptoms in just two weeks at the patients included in this group. We applied the same test at the hospital control group, but there was no decrease of depression's symptoms registered in the second group $(p=0,34)$. In the "Puterea Sperantei Project" control group there was not registered a decrease of depression symptoms $(\mathrm{p}=0,136)$.

The second questionnaire we applied was to evaluate the quality of life and functionality for patients included in the study. In the study group we observed an amelioration of quality of life at the end of the study comparing to the beginning $(p=0,005)$. Also, in the hospital control group the quality of life increased $(p=0,008)$, probably due to change of medication which covered patient's symptomatology by that time. In the "Puterea Sperantei Project" control group, the compliance was low, patients did not complete this questionnaire.

We also developed a questionnaire for dance therapy satisfaction, in order to appreciate how patients felt, if they will recommend this therapy to other patients, how did the therapy improved their daily's activities and how beneficial they considered it over all. This questionnaire was applied only in the study group and the feedback was positive, most of them being satisfied with the therapy they followed and 7 out of 10 patients would strongly recommend dance therapy to Parkinson disease patients.

In the dance therapy the group interaction played an important role, by the fact that patients were encouraging each other to give their best, help each other when needed, spent pleasant time together and 
be thankful for everyday progress. Happiness and big smiles came together with the struggles of correct execution of the moves, and with focus and acceptance.

\subsection{Limitations}

The small number of patients included in the study was due to variability of groups that were organized at the private center, being a problem at getting enough people together in order to create a group and also the inconsistency of timetable and classes at the private rehabilitation center.

The groups were not from the same place because due to logistical reasons it was imposible to implement the dance therapy classes in the hospital and also patients were not present in the same time in the hospital in order to create a homogenous group as we did at the private center.

Time was another limitation, total therapy time at the private center was 2 hours, and due to logistical reasons it was difficult to spend more time on working with the group. The time limitation also impacted on our possibility to deliver questionnaires and apply tests to patients. Especially in the "Puterea Sperantei Project" control group this was observed more acute as patients did not want to spent time that was planned for their therapy on filling out questionnaires.

\section{Conclusion}

Dance therapy is a non-pharmacological therapy which in our study shows encouraging results in decreasing patients depression's symptoms and increasing the quality of life, probably due to group integration, music influences, the capability of executing simple moves, the ability to express themselves though dance moves which offers them a holistic and pleasant experience. It is the first study in Romania which introduces dance therapy in rehabilitation programs of Parkinson disease patients. Extended studies needs to be done, in groups from the same place in order to be able to extrapolate our findings.

\section{Appendix}

\begin{tabular}{|c|c|}
\hline $\begin{array}{l}\text { 1. Were your expectations } \\
\text { fulfilled by "Puterea } \\
\text { sperantei project"? } \\
\text { 0- Not at all } \\
\text { 1- Not really } \\
\text { 2- Undecided } \\
\text { 3- Somewhat } \\
\text { 4- Very much }\end{array}$ & $\begin{array}{l}\text { 7. Did dance therapy help } \\
\text { you conduct better your } \\
\text { daily activities? } \\
0 \text { - Not at all } \\
\text { 1- Not really } \\
\text { 2- Undecided } \\
\text { 3- Somewhat } \\
\text { 4- Very much }\end{array}$ \\
\hline $\begin{array}{l}\text { 2. Do you consider the } \\
\text { activities room proper? } \\
0 \text { - Not at all } \\
\text { 1- Not really } \\
\text { 2- Undecided } \\
\text { 3- Somewhat } \\
\text { 4- Very much }\end{array}$ & $\begin{array}{l}\text { 8. Did dance therapy help } \\
\text { you perform } 2 / 3 \\
\text { simultaneous actions which } \\
\text { before were hard to } \\
\text { perform? } \\
\text { 0- Not at all } \\
\text { 1- Not really } \\
\text { 2- Undecided } \\
\text { 3- Somewhat } \\
\text { 4- Very much }\end{array}$ \\
\hline $\begin{array}{l}\text { 3.Did you get explications } \\
\text { about the exercises you } \\
\text { were about do to and their } \\
\text { benefit? } \\
\text { 0- Not at all } \\
\text { 1- Not really } \\
\text { 2- Undecided } \\
\text { 3- Somewhat } \\
\text { 4- Very much }\end{array}$ & $\begin{array}{l}\text { 9. Do you consider the } \\
\text { moves included were } \\
\text { properly chosen? } \\
\text { 0- Not at all } \\
\text { 1- Not really } \\
\text { 2- Undecided } \\
\text { 3- Somewhat } \\
\text { 4- Very much }\end{array}$ \\
\hline $\begin{array}{l}\text { 4.Did you feel safe during } \\
\text { the program? } \\
\text { 0- Not at all } \\
\text { 1- Not really } \\
\text { 2- Undecided } \\
\text { 3- Somewhat } \\
\text { 4- Very much }\end{array}$ & $\begin{array}{l}\text { 10. How do you evaluate } \\
\text { your communication with } \\
\text { the coordinator of dance } \\
\text { therapy? } \\
\text { 0- Not at all } \\
\text { 1- Not really } \\
\text { 2- Undecided } \\
\text { 3- Somewhat } \\
\text { 4- Very much }\end{array}$ \\
\hline $\begin{array}{l}\text { 5. Do you consider dance } \\
\text { therapy helped your } \\
\text { mobility? } \\
\text { 0- Not at all } \\
\text { 1- Not really } \\
\text { 2- Undecided } \\
\text { 3- Somewhat } \\
\text { 4- Very much }\end{array}$ & $\begin{array}{l}\text { 11. What is your overall } \\
\text { opinion about dance } \\
\text { therapy at the end of two } \\
\text { weeks therapy? } \\
0 \text { - Not at all } \\
\text { 1- Not really } \\
\text { 2- Undecided } \\
\text { 3- Somewhat } \\
\text { 4- Very much }\end{array}$ \\
\hline $\begin{array}{l}\text { 6. Do you consider dance } \\
\text { therapy helped you exceed } \\
\text { though freezing events? } \\
0 \text { - Not at all } \\
\text { 1- Not really } \\
\text { 2- Undecided } \\
\text { 3- Somewhat } \\
\text { 4- Very much }\end{array}$ & $\begin{array}{l}\text { 12. Will you recommend } \\
\text { dance therapy to other } \\
\text { persons? } \\
\text { 0- Not at all } \\
\text { 1- Not really } \\
\text { 2- Undecided } \\
\text { 3- Somewhat } \\
\text { 4- Very much }\end{array}$ \\
\hline
\end{tabular}




\section{References:}

1. Tarsy D. Treatment of Parkinson Disease: A 64Year-Old Man With Motor Complications of Advanced Parkinson Disease. JAMA. 2012 Jun 6;307(21):2305-14.

2. Olanow CW, Stern MB, Sethi K. The scientific and clinical basis for the treatment of Parkinson disease (2009). Neurology. 2009 May 26;72(21 Suppl 4):S1-136.

3. Connolly BS, Lang AE. Pharmacological Treatment of Parkinson Disease: A Review. JAMA. 2014 Apr 23;311(16):1670-83.

4. Gelb DJ, Oliver E, Gilman S. Diagnostic Criteria for Parkinson Disease. Arch Neurol. 1999 Jan 1;56(1):33-9.

5. Cook Shukla L, Schulze J, Farlow J, Pankratz ND, Wojcieszek J, Foroud T. Parkinson Disease Overview. In: Adam MP, Ardinger HH, Pagon RA, Wallace SE, Bean LJ, Stephens K, et al., editors. GeneReviews ${ }^{\circledR} \quad$ [Internet]. Seattle (WA): University of Washington, Seattle; 1993 [cited 2019 Aug 10]. Available from: http://www.ncbi.nlm.nih.gov/books/NBK1223/

6. Chaudhuri KR, Healy DG, Schapira AH. Nonmotor symptoms of Parkinson's disease: diagnosis and management. Lancet Neurol. 2006 Mar 1;5(3):235-45.

7. LeWitt PA, Fahn S. Levodopa therapy for Parkinson disease: A look backward and forward. Neurology. 2016 Apr 5;86(14 Supplement 1):S3-12.

8. Bloem BR, de Vries NM, Ebersbach G. Nonpharmacological treatments for patients with Parkinson's disease. Mov Disord Off J Mov Disord Soc. 2015 Sep 15;30(11):1504-20.

9. Svensson M, Lexell J, Deierborg T. Effects of Physical Exercise on Neuroinflammation, Neuroplasticity, Neurodegeneration, and Behavior: What We Can Learn From Animal Models in Clinical Settings. Neurorehabil Neural Repair. 2015 Jul;29(6):577-89.

10. Dhami P, Moreno S, DeSouza JFX. New framework for rehabilitation - fusion of cognitive and physical rehabilitation: the hope for dancing. Front Psychol [Internet]. 2015 Jan 28 [cited 2018 May 2];5. Available from: https://www.ncbi.nlm.nih.gov/pmc/articles/PM C4309167/
11. Särkämö T. Cognitive, emotional, and neural benefits of musical leisure activities in aging and neurological rehabilitation: A critical review. Ann Phys Rehabil Med. 2017 Apr 28;

12. Saarikallio S. Music as emotional selfregulation throughout adulthood. Psychol Music. 2011 Jul;39(3):307-27.

13. Fukui H, Toyoshima K. Music facilitate the neurogenesis, regeneration and repair of neurons. Med Hypotheses. 2008 Nov;71(5):765-9.

14. Brown S, Martinez MJ, Parsons LM. The neural basis of human dance. Cereb Cortex N Y N 1991. 2006 Aug;16(8):1157-67.

15. Engineer ND, Percaccio CR, Pandya PK, Moucha R, Rathbun DL, Kilgard MP. Environmental enrichment improves response strength, threshold, selectivity, and latency of auditory cortex neurons. J Neurophysiol. 2004 Jul;92(1):73-82.

16. Angelucci F, Ricci E, Padua L, Sabino A, Tonali PA. Music exposure differentially alters the levels of brain-derived neurotrophic factor and nerve growth factor in the mouse hypothalamus. Neurosci Lett. 2007 Dec $18 ; 429(2-3): 152-5$.

17. Likert R. A technique for the measurement of attitudes. Arch Psychol. 1932;

18. Beck AT, Steer RA, Carbin MG. Psychometric properties of the Beck Depression Inventory: Twenty-five years of evaluation. Clin Psychol Rev. 1988 Jan 1;8(1):77-100.

19. Hagell P, Nygren C. The 39 item Parkinson's disease questionnaire (PDQ-39) revisited: implications for evidence based medicine. J Neurol Neurosurg Psychiatry. 2007 Nov;78(11):1191-8.

20. Dance for PD [Internet]. [cited 2019 Aug 7]. Available from: https://danceforparkinsons.org/. 